\title{
Growth Hormone-induced Nitrogen Retention in Children of Short Stature
}

\author{
G. A. BROWN, L. STIMMLER, and J. G. LINES \\ From the Institute of Child Health, University of Birmingham and the Department of Biochemistry, \\ Children's Hospital, Birmingham 16
}

The decrease in urinary nitrogen excretion (i.e. increased nitrogen retention) following intramuscular injection of human growth hormone (HGH) has been used to differentiate hypopituitary dwarfism from other types of short stature. While small decreases can be demonstrated in almost all children who are given HGH, in the hypopituitary child the decrease is greater and more prolonged. Using a standardized test of nitrogen retention in response to $\mathrm{HGH}$, Prader, Illig, Széky, and Wagner (1964) recorded very little overlap when the results in a group of 12 hypopituitary dwarfs were compared with those of 7 non-hypopituitary dwarfs and 4 children of normal stature. In the first Lawson Wilkins Memorial Lecture, Hubble (1966) reported no overlap of results using a similar $\mathrm{HGH}$ nitrogen retention test in a group of 10 dwarfed children, 6 of whom had hypopituitarism. This series of patients has now been extended to 22 cases. The results of

Received November 3, 1966. the $\mathrm{HGH}$ nitrogen retention test in the whole series are reported here.

\section{Materials and Methods}

Investigations were made on 22 children, 8 girls and 14 boys, with an age range of 7-19 years (Table I). All 22 children were below the 3rd centile for height. 10 showed clinical and biochemical evidence of hypopituitarism (Cases 1-10) and were so diagnosed before the nitrogen retention test was undertaken. The cause of short stature in the remaining 12 children was unknown, but in 3 of them (Cases 39, 40, and 41) a diagnosis of intrauterine growth retardation had been made. In 1 patient (Case 14), with no evidence of hypopituitarism, the plasma growth hormone response to insulin-induced hypoglycaemia (Stimmler and Brown, 1967) was no greater than that seen in the hypopituitary children.

A summary of the clinical, biochemical, and radiological findings in Cases 1-10 appears in the preceding paper by Hubble on the diagnosis of hypopituitarism, and for Cases 11-14 in the preceding paper by Stimmler and Brown.

TABLE I

Details of Patients Investigated

\begin{tabular}{|c|c|c|c|c|c|}
\hline Case No. & Sex & Age (yr.) & Height (cm.) & Weight (kg.) & Diagnosis \\
\hline $\begin{array}{r}1 \\
2 \\
3 \\
4 \\
5 \\
6 \\
7 \\
8 \\
9 \\
10 \\
14 \\
18 \\
20 \\
22 \\
25 \\
27 \\
30 \\
31 \\
32 \\
39 \\
40 \\
41\end{array}$ & $\begin{array}{l}\mathbf{F} \\
\mathbf{F} \\
\mathbf{F} \\
\mathbf{M} \\
\mathbf{M} \\
\mathbf{M} \\
\mathbf{M} \\
\mathbf{F} \\
\mathbf{M} \\
\mathbf{F} \\
\mathbf{M} \\
\mathbf{M} \\
\mathbf{M} \\
\mathbf{M} \\
\mathbf{M} \\
\mathbf{F} \\
\mathbf{M} \\
\mathbf{M} \\
\mathbf{M} \\
\mathbf{F} \\
\mathbf{F} \\
\mathbf{M}\end{array}$ & $\begin{array}{r}8 \\
13 \\
19 \\
13 \\
12 \\
14 \\
11 \\
15 \\
17 \\
12 \\
10 \\
10 \\
9 \\
12 \\
8 \\
8 \\
9 \\
10 \\
9 \\
7 \\
12 \\
8\end{array}$ & $\begin{array}{r}98 \\
122 \\
144 \\
129 \\
125 \\
135 \\
123 \\
113 \\
152 \\
125 \\
120 \\
117 \\
116 \\
131 \\
118 \\
109 \\
108 \\
117 \\
122 \\
99 \\
113 \\
108\end{array}$ & $\begin{array}{l}16 \cdot 6 \\
41 \cdot 3 \\
29 \cdot 1 \\
28 \cdot 4 \\
40 \cdot 9 \\
34 \cdot 8 \\
25 \cdot 5 \\
24 \cdot 1 \\
44 \cdot 3 \\
25 \cdot 2 \\
28 \cdot 0 \\
19 \cdot 8 \\
19 \cdot 9 \\
26 \cdot 0 \\
20 \cdot 7 \\
16 \cdot 1 \\
19 \cdot 5 \\
21 \cdot 8 \\
22 \cdot 4 \\
12 \cdot 7 \\
19 \cdot 3 \\
15 \cdot 1\end{array}$ & $\begin{array}{l}\text { Hypopituitary short stature } \\
\text { Hypopituitary short stature } \\
\text { Hypopituitary short stature } \\
\text { Hypopituitary short stature } \\
\text { Hypopituitary short stature } \\
\text { Hypopituitary short stature } \\
\text { Hypopituitary short stature } \\
\text { Hypopituitary short stature } \\
\text { Hypopituitary short stature } \\
\text { Hypopituitary short stature } \\
\text { Short stature of unknown aetiology } \\
\text { Short stature of unknown aetiology } \\
\text { Short stature of unknown aetiology } \\
\text { Short stature of unknown aetiology } \\
\text { Short stature of unknown aetiology } \\
\text { Short stature of unknown aetiology } \\
\text { Short stature of unknown aetiology } \\
\text { Short stature of unknown aetiology } \\
\text { Short stature of unknown aetiology } \\
\text { Intrauterine growth retardation } \\
\text { Intrauterine growth retardation } \\
\text { Intrauterine growth retardation }\end{array}$ \\
\hline
\end{tabular}


TABLE II

Nitrogen Retention Tests

\begin{tabular}{|c|c|c|c|c|c|}
\hline \multirow{2}{*}{ Case No. } & \multicolumn{3}{|c|}{ Mean Daily Nitrogen Excretion (g./24 hr.) } & \multirow{2}{*}{$\begin{array}{c}\text { Percentage } \\
\text { Nitrogen } \\
\text { Retention }\end{array}$} & \multirow{2}{*}{$\begin{array}{c}\text { Nitrogen } \\
\text { Retention } \\
\text { (mg./kg. } 24 \text { hr.) }\end{array}$} \\
\hline & Pre-HGH & On HGH & Post-HGH & & \\
\hline $\begin{array}{r}1 \\
2 \\
3 \\
4 \\
5 \\
6 \\
7 \\
8 \\
9 \\
10\end{array}$ & $\begin{array}{c}5 \cdot 2(7)^{\star} \\
9.8(6) \\
8 \cdot 2(7) \\
6 \cdot 5(5) \\
6 \cdot 2(6) \\
6.6(9) \\
8 \cdot 1(5) \\
3.6(5) \\
10.9(6) \\
5.9(6)\end{array}$ & $\begin{array}{c}\text { Hypopituitar } \\
3 \cdot 4(6) \\
5 \cdot 2(6) \\
4 \cdot 0(6) \\
3 \cdot 6(5) \\
3 \cdot 3(7) \\
4 \cdot 1(7) \\
4 \cdot 9(5) \\
1 \cdot 9(5) \\
6 \cdot 0(8) \\
2 \cdot 9(11)\end{array}$ & $\begin{array}{c}\text { ure, } 10 \text { Cases } \\
4 \cdot 2(4) \\
10 \cdot 1(4) \\
6 \cdot \overline{1}(5) \\
= \\
6 \cdot \overline{1}(5) \\
3 \cdot 3(5) \\
8 \cdot 0(2) \\
5 \cdot 6(3)\end{array}$ & $\begin{array}{l}35 \\
51 \\
51 \\
45 \\
52 \\
42 \\
40 \\
47 \\
45 \\
51\end{array}$ & $\begin{array}{r}108 \\
121 \\
107 \\
102 \\
78 \\
80 \\
125 \\
71 \\
111 \\
119\end{array}$ \\
\hline $\begin{array}{l}14 \\
18 \\
20 \\
22 \\
25 \\
27 \\
30 \\
31 \\
32 \\
39 \\
40 \\
41\end{array}$ & $\begin{array}{l}6 \cdot 6(7) \\
6 \cdot 5(8) \\
6 \cdot 2(5) \\
7 \cdot 2(5) \\
4 \cdot 6(5) \\
4 \cdot 7(5) \\
3 \cdot 0(4) \\
5 \cdot 5(8) \\
6 \cdot 6(5) \\
1 \cdot 8(5) \\
7 \cdot 3(5) \\
5 \cdot 2(5)\end{array}$ & $\begin{array}{c}\text { Non-Hypopitui } \\
5 \cdot 3(9) \\
6 \cdot 1(7) \\
6 \cdot 9(5) \\
6 \cdot 6(5) \\
4 \cdot 5(6) \\
4 \cdot 5(5) \\
2 \cdot 7(4) \\
5 \cdot 2(7) \\
5 \cdot 5(5) \\
2 \cdot 0(5) \\
6 \cdot 5(5) \\
4 \cdot 2(5)\end{array}$ & $\begin{array}{c}\text { tature, } 12 \text { Cases } \\
7 \cdot 3(4) \\
8 \cdot 4(6) \\
7 \cdot 3(5) \\
4 \cdot \overline{6}(3) \\
4 \cdot 8(5) \\
4 \cdot 1(5) \\
7 \cdot 4(6) \\
7 \cdot 2(5) \\
7 \cdot 3(5) \\
5 \cdot 6(5)\end{array}$ & $\begin{array}{r}23 \\
8 \\
-11 \dagger \\
8 \\
2 \\
4 \\
17 \\
5 \\
17 \\
-11 \dagger \\
7 \\
19\end{array}$ & $\begin{array}{c}54 \\
25 \\
-35 t \\
23 \\
5 \\
12 \\
26 \\
14 \\
49 \\
-16 t \\
26 \\
66\end{array}$ \\
\hline
\end{tabular}

* Figures in parentheses show the duration in days of each test period.

$t$ The negative sign indicates an apparent decrease of nitrogen retention in the growth hormone period. The two negative results are omitted from Fig. 2-4.

Nitrogen retention test. The test was divided into three periods: a baseline or pre-HGH period; an $\mathrm{HGH}$ period, during which the patients received intramuscular injections of the hormone at 9 a.m. daily; and a withdrawal or post-HGH period. The duration of the test periods varied (Table II). In the latter part of the study a standardized form was adopted in which each period lasted for 5 days. Though the test had to be modified or curtailed to suit individual patients, all but one of the

TABLE III

HGH Dose Rates and Dietary Protein in Nitrogen Retention Tests

\begin{tabular}{|c|c|c|}
\hline Case No. & $\begin{array}{l}\text { HGH Dose } \\
\text { i.u./kg. } 24 \mathrm{hr} .\end{array}$ & $\begin{array}{c}\text { Dietary Protein } \\
\text { g./kg. } 24 \text { hr. }\end{array}$ \\
\hline $\begin{array}{r}1 \\
2 \\
3 \\
4 \\
5 \\
6 \\
7 \\
8 \\
9 \\
10 \\
14 \\
18 \\
20 \\
22 \\
25 \\
27 \\
30 \\
31 \\
32 \\
39 \\
40 \\
41\end{array}$ & $\begin{array}{l}0.8 \\
0.2 \\
0.3 \\
0.2 \\
0.3 \\
0.4 \\
0.5 \\
0.5 \\
0.3 \\
0.5 \\
0.5 \\
0.6 \\
0.3 \\
0.5 \\
0.6 \\
0.4 \\
0.3 \\
0.6 \\
0.3 \\
0.5 \\
0.3 \\
0.4\end{array}$ & $\begin{array}{l}2 \cdot 8 \\
2 \cdot 4 \\
1 \cdot 4 \\
1 \cdot 8 \\
1 \cdot 1 \\
1 \cdot 1 \\
3 \cdot 0 \\
2 \cdot 1 \\
1 \cdot 5 \\
1 \cdot 9 \\
2 \cdot 1 \\
2 \cdot 1 \\
3 \cdot 0 \\
2 \cdot 0 \\
2 \cdot 1 \\
2 \cdot 3 \\
2 \cdot 3 \\
2 \cdot 8 \\
2 \cdot 3 \\
2 \cdot 4 \\
2 \cdot 4 \\
2 \cdot 8\end{array}$ \\
\hline
\end{tabular}

children received HGH (Medical Research Council Raben preparation batches $R$ 6-9) for at least 5 days. The daily dose of hormone was $10 \mathrm{mg}$. (the contents of one Medical Research Council ampoule). In 6 of the tests, where the potency of the HGH batch was approximately half that previously used, the daily injection was increased to $20 \mathrm{mg}$. The resulting dose rate (Table III)

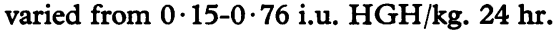

The children received a constant daily diet of known protein content starting 2 or 3 days before the pre-HGH period and lasting throughout the test. The diets were largely selected by the patients themselves during their first few days in hospital. The resulting daily dietary protein intake (Table III) ranged from $1 \cdot 1-3 \cdot 0 \mathrm{~g} . / \mathrm{kg}$. $24 \mathrm{hr}$.

All urine passed during the test was collected in 24-hour volumes, starting and finishing at 10 a.m. each day. The total nitrogen content of each day's collection was measured and a mean daily nitrogen excretion was calculated for each of the three periods of the test. In the case of the HGH period, the first 24 hours were omitted from the calculation of the mean since it was considered that nitrogen excretion in this transitional stage would be characteristic of neither the baseline nor the growth hormone period. Similar omission of the first 24 hours of the withdrawal period was not thought to be justified since it has been shown (Medical Research Council, 1959) that, in the hypopituitary patients at least, the return of nitrogen excretion to baseline levels may be delayed for several days.

An increase in nitrogen retention in response to $\mathrm{HGH}$ was recorded when the mean daily excretion for the HGH period was less than that of the baseline period. The 
increased retention was recorded in two ways. The first gave nitrogen retention by the convention recommended by Metcalf and Greene (1963), in which the decrease in nitrogen excretion was expressed as a percentage of the baseline nitrogen excretion, i.e.

Percentage nitrogen retention $=\frac{A-B}{A} \times 100$,

where $\mathbf{A}=$ mean daily nitrogen excretion in the baseline period and $\mathbf{B}=$ mean daily nitrogen excretion in the HGH period.

In the second method the difference between the mean daily nitrogen excretion for the baseline and HGH periods was related to body weight and the nitrogen retained expressed as mg. $\mathrm{N}$ retained $/ \mathrm{kg} .24 \mathrm{hr}$.

Analytical methods. All urine collections were preserved with acetic acid and stored at $4^{\circ} \mathrm{C}$. until analysed. Solutes precipitated from the urine by low temperature storage were redissolved before analysis by warming at $37^{\circ} \mathrm{C}$. for a short period. Any material remaining undissolved (mostly urinary tract mucoprotein) was removed by centrifugation before analysis.

Total urinary nitrogen concentration was estimated in the first 10 nitrogen retention tests using a microKjeldahl procedure. All subsequent nitrogen analyses were done by a semi-automated technique in which the urines were first digested manually, using the conditions recommended by Fleck and Munro (1965). The ammonia content of the digest was then measured on the Technicon AutoAnalyzer by the phenol-hypochlorite reaction, using the appropriate section of the AutoAnalyzer total nitrogen manifold (Technicon Instruments Co. Ltd., 1962).

\section{Results}

Response to growth hormone administration. The mean daily urine nitrogen excretion in each of the three periods of the test are shown in Fig. 1 and Table II, together with the two quantitative expressions for nitrogen retention. Some nitrogen retention occurred in all but 2 of the 22 children. In these 2 (Cases 20 and 39) nitrogen retention appeared to have decreased on administration of $\mathrm{HGH}$. Creatinine excretion in the $\mathrm{HGH}$ period in these two tests was apparently $25 \%$ and $68 \%$ greater than the baseline period excretion. The discrepancy suggests that these two anomalous results may have been the consequence of inadequate urine collection. These two results appear in the Tables, but for the sake of simplicity have been omitted from Fig. 2-4.

The greatest increase in nitrogen retention was shown in those children who were thought to be hypopituitary dwarfs. Nitrogen retention ranged from $35-52 \%$ and retention on a body weight basis from 71-125 mg./kg. $24 \mathrm{hr}$. Percentage nitrogen retention for the non-hypopituitary dwarfed children ranged from the two values apparently recording

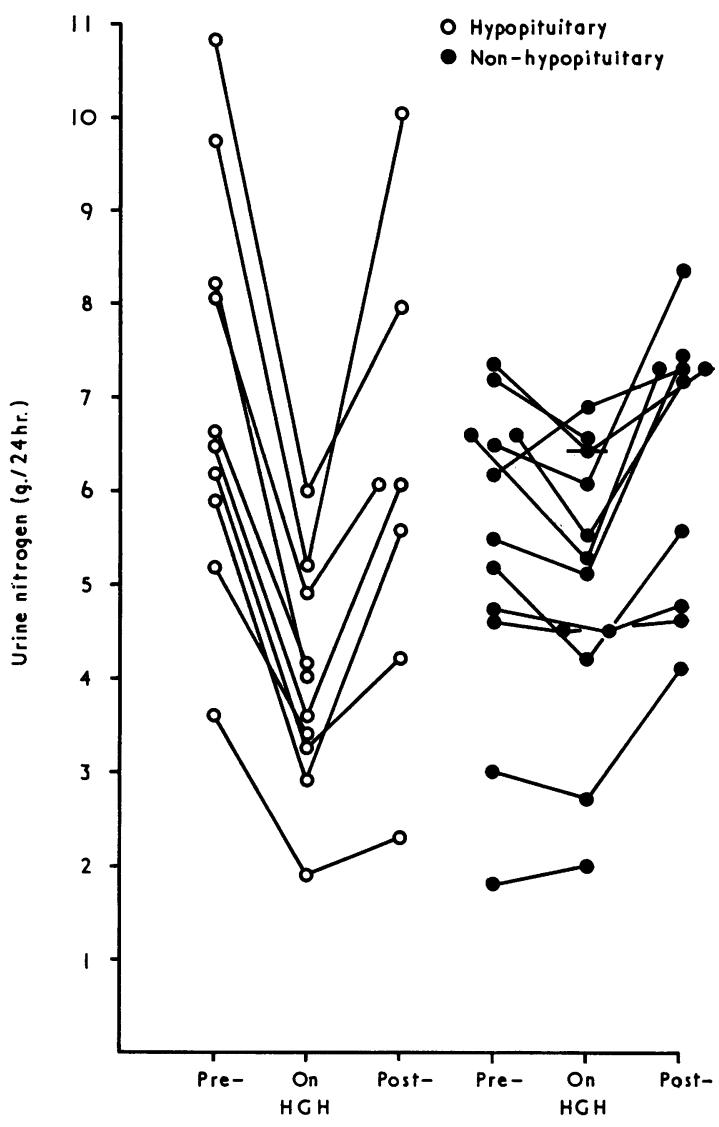

FIG. 1.-Mean daily nitrogen excretion in the three periods of the nitrogen retention test.

decreased retention to an increased retention of $19 \%$. Values up to $66 \mathrm{mg}$. $/ \mathrm{kg}$. $24 \mathrm{hr}$. were recorded for the body weight parameter. In the boy with low growth hormone levels in the insulin sensitivity test, but with no other evidence of hypopituitarism, nitrogen retention was $23 \%$ or $54 \mathrm{mg} . / \mathrm{kg}$. $24 \mathrm{hr}$. This percentage nitrogen retention level was higher than the values recorded for the rest of the nonhypopituitary children, but considerably lower than the lowest value (35\%) in the hypopituitary cases. On a body weight basis the nitrogen retention figure was also lower than the lowest hypopituitary figure of $71 \mathrm{mg}$. $/ \mathrm{kg}$. $24 \mathrm{hr}$. (Case 8).

Response to growth hormone withdrawal. In all but one (Case 2) of the 7 hypopituitary children in whom nitrogen excretion was measured after HGH administration had ceased, the mean daily nitrogen excretion for the withdrawal period 


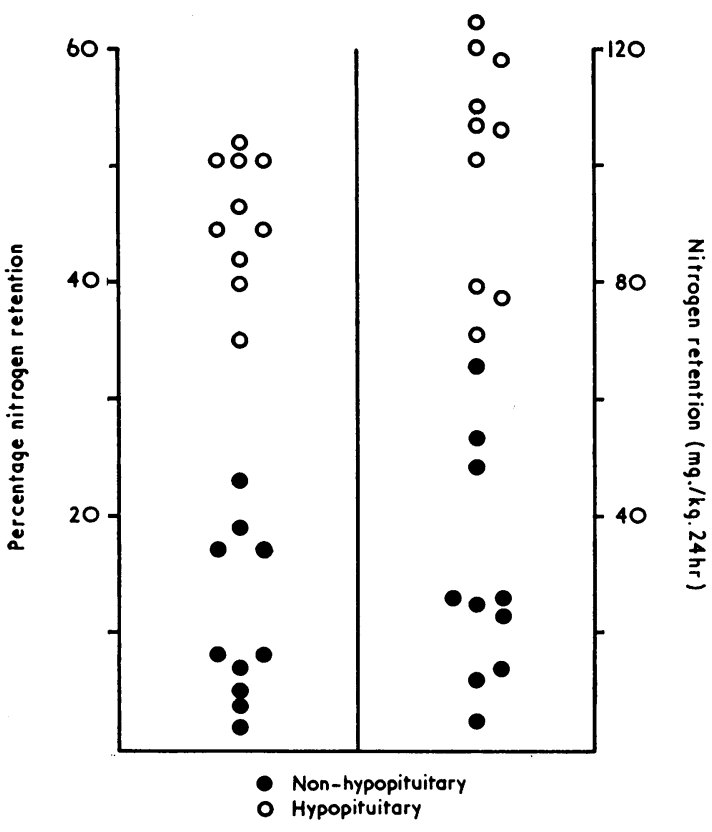

FIG. 2.-Nitrogen retention test results.

was less than that of the baseline period. In 2 (Cases 9 and 10), however, the duration of the postHGH period was only of 2 and 3 days, respectively, and the results cannot be fairly compared with a 5 -day baseline period. In the remaining 5 children for whom the post-HGH period was of 4 or 5 days'

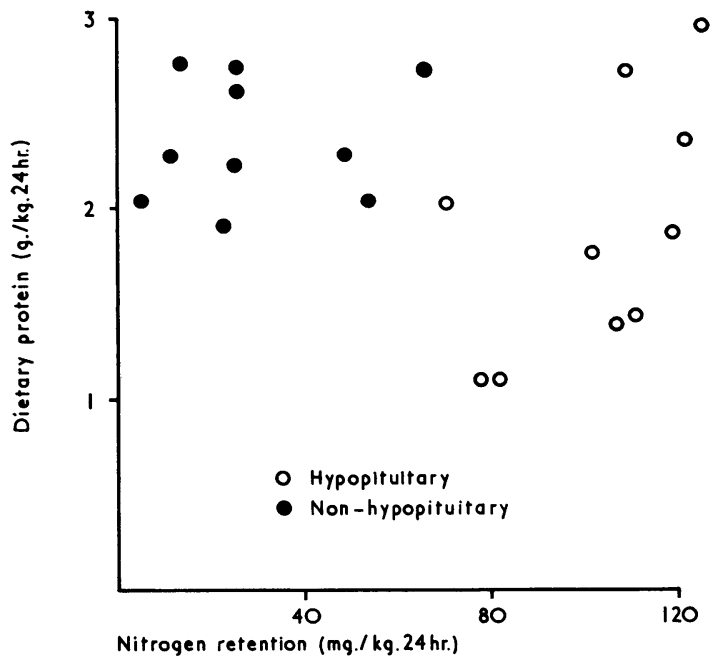

FIG. 3.-The relation between dietary protein intake and nitrogen retention. duration, the increase in nitrogen retention continued for variable periods after growth hormone administration had ceased. The time taken for the daily nitrogen excretion to return to, or to exceed, the baseline mean varied from one day (Case 2) to a failure to return during the whole of the 5 days of the post-HGH period (Case 7).

In the 10 non-hypopituitary children in whom

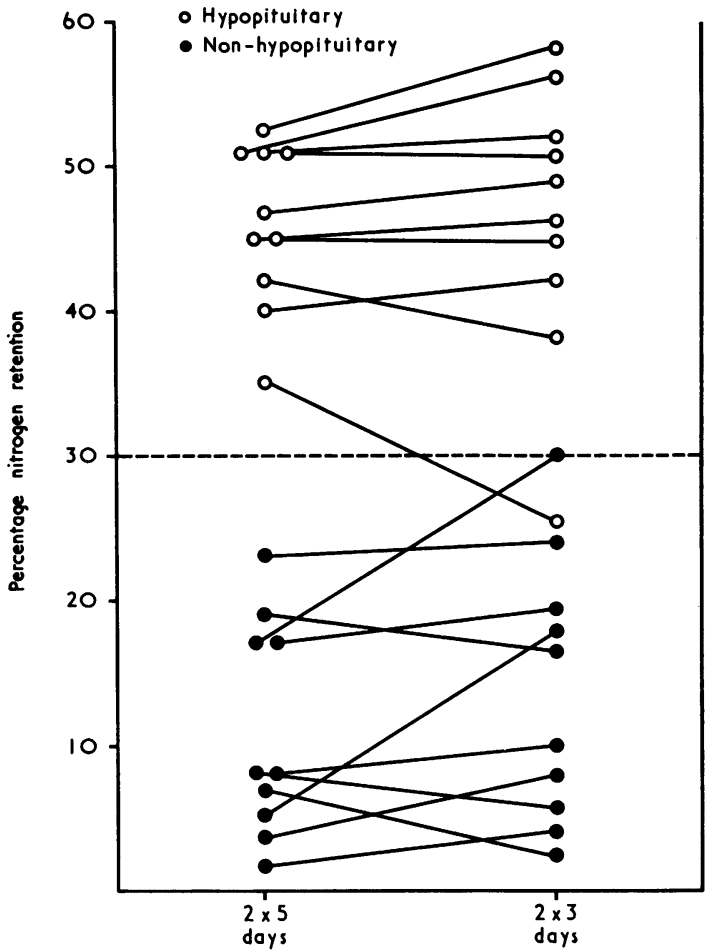

FIG. 4.-Nitrogen retention results calculated from the complete tests compared with the results calculated by using only 3 days' data from each period.

nitrogen excretion was measured after withdrawal of $\mathrm{HGH}$, the mean daily nitrogen excretion was either equal to ( 3 cases) or greater than ( 7 cases) the baseline excretion. The magnitude of this rebound in nitrogen excretion was sufficiently great in 4 of the children to produce a net negative nitrogen balance at the end of the test.

Nitrogen retention in the 3 patients with intrauterine growth retardation was indistinguishable from that of the other non-hypopituitary children.

\section{Discussion}

The results of the nitrogen retention tests in the 22 children studied correlate well with the clinical 
assessment. The hypopituitary and non-hypopituitary children could be separated by arbitrary lines drawn at $30 \%$ nitrogen retention and at $70 \mathrm{mg}$. $\mathrm{N} / \mathrm{kg}$. 24 hr. (Fig. 2). These levels are very similar to those that divide the hypopituitary from nonhypopituitary children in the investigation of dwarfed children reported by Prader et al. (1964). The continued retention of nitrogen by the hypopituitary children after withdrawal of $\mathrm{HGH}$, and the rapid rebound in nitrogen excretion in the majority of the non-hypopituitary children, were additional distinguishing features.

Rebound of nitrogen excretion on withdrawal of HGH has been described in the rat (Lee, 1938), in the dog (Gaebler, Bartlett, and Sweeney, 1951), and in man (Medical Research Council, 1959). The mechanism is unknown. Examination of our data shows that neither the $\mathrm{HGH}$ dose, the protein intake, nor the product of the two were related to the magnitude of the rebound. Hubble (1966) has postulated the occurrence of temporary suppression of pituitary function by the exogenous hormone. Munro (1964) has suggested that the rebound phenomenon is due to elimination of nitrogen temporarily accumulated as 'labile body protein' in response to the hormone. This mechanism alone would not explain the rebound in Cases 18, 30, and 31 where the nitrogen excreted in the post-HGH period was considerably greater than the total additional nitrogen retained in the HGH period.

Influence of HGH dosage. All the children, irrespective of size, received approximately the same quantity of $\mathrm{HGH}$ in terms of biological activity. This amounted to $10 \mathrm{mg}$./day for all but 6 of the children, the latter receiving $20 \mathrm{mg}$./day of a $\mathrm{HGH}$ preparation having approximately half the activity of the batches used in the rest of the tests. The dose rate for different children, therefore, varied considerably, ranging from $0 \cdot 15$ i.u. in the largest child to 0.76 i.u. $\mathrm{HGH} / \mathrm{kg}$. $24 \mathrm{hr}$. in the smallest. No difference, however, was seen in the response to the hormone which could be ascribed to the varying dose rate. The higher dose rates did not produce greater nitrogen retention in either the hypopituitary or non-hypopituitary children. The mean dose rate in this study $(0.42$ i.u./kg. $24 \mathrm{hr}$. $)$ was approximately three times the physiological replacement dose of $2 \mathrm{mg}$./sq. m. body surface area in 24 hours, used by Prader et al. (1964). The percentage nitrogen retentions reported in their study, and in ours, for hypopituitary and non-hypopituitary children are very similar. Thus, dose rates of this order of magnitude above the physiological requirement appear to have little further influence on the degree of nitrogen retention. Animal experiment has shown that very large increases in the amount of growth hormone may induce greater nitrogen retention. Marx, Simpson, and Evans (1942) showed a logarithmic relation between weight gain and the dose of a growth hormone preparation given to normal rats. Weight gain in the rats was doubled by a tenfold multiplication of the amount of growth hormone used. The results reported here, however, suggest that the patient's growth hormone deficiency was the major factor influencing the response to $\mathrm{HGH}$ in the nitrogen retention test. The calculated 24-hour body requirement is adequate for near maximal response. Considerable dose increases above this level do not appear to result in an appreciably greater retention of nitrogen.

Influence of dietary protein. The selection of the test period diets by the children themselves resulted in considerable variation of daily protein intake, ranging from $1 \cdot 1 \mathrm{~g}$. to $3.0 \mathrm{~g}$. protein $/ \mathrm{kg} .24$ hr. (Table III). The hypopituitary children tended to select diets with a lower protein content, 6 of the 10 having a mean daily protein intake lower than any of the non-hypopituitary children. Nitrogen retention in the non-hypopituitary children was not apparently influenced by their protein intake (Fig. 3). In the hypopituitary children, though a positive correlation was suggested between protein intake and nitrogen retention (Fig. 3), the coefficient of correlation was not significant $(p=0 \cdot 05-0 \cdot 10)$.

Expression of results. The calculation of percentage nitrogen retention relates the decrease in nitrogen excretion on $\mathrm{HGH}$ administration to the nitrogen excretion in the pre-HGH period. Since the latter is approximately equal to protein nitrogen ingestion, and nitrogen retention has been seen not to be influenced by the level of protein consumption, nitrogen retention recorded by this method will be influenced not only by hormonal action but also by the level of protein consumption during the test. Low protein consumption will tend to give high percentage nitrogen retention figures, and high protein consumption low percentage nitrogen retention figures. The selection of diets of lower protein content by the hypopituitary children would tend to produce high percentage nitrogen figures. The fact that the hypopituitary and non-hypopituitary children are apparently better separated by the percentage retention expression compared with the figures for nitrogen retention on a body weight basis (Fig. 2) may be the result of the difference in mean level of protein consumption. In practice, 
however, both methods of expressing the test results may be adequate, and in this study both have produced the same segregation of patients.

Shortened nitrogen retention test. The nitrogen retention test used in this study is a protracted and difficult investigation, entailing admission of the patient to hospital for at least two weeks. The difficulties are largely practical ones of ward management. The children must be maintained on the same daily diet for 15 days; a period sufficiently long to result in loss of appetite in many patients. Urines must be accurately collected night and day for the whole period, a task that can only be accomplished satisfactorily in a unit organized for metabolic investigations. For the whole of the test period the patients should be maintained in equilibrium without the intervention of other factors, e.g. infection or loss of appetite, which may modify urinary nitrogen excretion. Several tests were either delayed, curtailed, or cancelled because of this kind of complication. Reducing the duration of the test would reduce the opportunity for interference by other factors and also the period of discomfort to the patient. Since this would also reduce the number of observations of urinary nitrogen and possibly therefore the accuracy of the test, the effect of this kind of modification was investigated by re-evaluating the data from the present series of tests. Mean daily nitrogen excretions were recalculated using the figures from two 3-day periods, the 3 days immediately before $\mathrm{HGH}$ and days $2-4$ of $\mathrm{HGH}$ administration. A comparison of the results produced in this way with the results using the complete periods of the tests is shown in Fig. 4. In 17 of the 22 tests, the results differed by $5 \%$ nitrogen retention or less. In the remaining 5 tests the differences were $6,9,10$, 13 , and $13 \%$, respectively. In 3 of them, though the change was appreciable, the result was still clearly characteristic of the group to which the patient belonged. Of the other 2 , one changed from a non-hypopituitary value of $17 \%$ to a borderline value of $30 \%$, and the other from a hypopituitary value of $35 \%$ down to a non-hypopituitary value of $25 \%$. This last test was the only one in which the re-evaluation resulted in an apparent change in the patient's category. In 21 of the 22 tests (95\%) the clinical significance of the test result was unchanged.

\section{Summary}

The nitrogen retention produced by administration of HGH was measured in 22 short children, 10 of whom were hypopituitary dwarfs. Increased nitrogen retention was recorded in all but 2 of the children. It was greater in the hypopituitary group, and the effect persisted for a longer period after withdrawal of $\mathrm{HGH}$. In the non-hypopituitary children a lesser degree of nitrogen retention was followed by a rapid return of nitrogen excretion to pre-HGH levels, or above. Though the nitrogen retention results for the two groups were not widely separated, no actual overlap occurred.

Nitrogen retention in the non-hypopituitary children was not related to $\mathrm{HGH}$ dose rate or protein intake during the test. In the hypopituitary children nitrogen retention was similarly unrelated to $\mathrm{HGH}$ dose rate, but a positive relation to protein intake was suggested. The correlation coefficient, however, was not significant.

The authors are indebted to Professor D. V. Hubble for his guidance and for permission to investigate his patients. Many members of the Children's Hospital nursing staff participated in the work, but special thanks are due to Sister Foster, and Sister Struthers, and to Sister Hilda Jukes, Hospital Dietitian, who was responsible for dietetic planning and management. Mr. David Smith gave expert assistance in the laboratory. The HGH was provided by the Medical Research Council.

\section{REFERENCES}

Fleck, A., and Munro, H. N. (1965). The determination of organic nitrogen in biological materials : a review. Clin. chim. Acta, 11, 2.

Gaebler, O. H., Bartlett, P. D., and Sweeney, M. J. (1951). Remarkable effectiveness of small daily doses of growth hormone in dogs. Amer. F. Physiol., 165, 486.

Hubble, D. (1966). Studies with human growth hormone. Arch. Dis. Childh., 41, 17.

Lee, M. O. (1938). In The Pituitary Gland, ed. W. Timme, A. M. Frantz, and C. C. Hare, p. 193. (Association for Research in Nervous and Mental Disease, Res. Publ., vol. 17.) Williams and Wilkins, Baltimore.

Marx, W., Simpson, M. E., and Evans, H. M. (1942). Bioassay of the growth hormone of the anterior pituitary. Endocrinology, $\mathbf{3 0}, 1$.

Medical Research Council (1959). The effectiveness in man of human growth hormone. Lancet, $1,7$.

Metcalf, W., and Greene, H. G. (1963). A quantitative expression for nitrogen retention with anabolic steroids. 1. Norethandrolone. Metabolism, 12, 899.

Munro, H. N. (1964). General aspects of the regulation of protein metabolism by diet and by hormones. In Mammalian Protein Metabolism, Vol. 1, ed. J. B. Allison and H. N. Munro, p. 381. Academic Press, New York and London.

Prader, A., Illig, R., Széky, J., and Wagner, H. (1964). The effect of human growth hormone in hypopituitary dwarfism. Arch. Dis. Childh., 39, 535.

Stimmler, L., and Brown, G. A. (1967). Growth hormone secretion provoked by insulin-induced hypoglycaemia in children of short stature. Arch. Dis. Childh., 42, 232.

Technicon Instruments Co. Ltd. (1962). Estimation of total nitrogen. AutoAnalyzer methodology bulletin No. N3a. 